\title{
THE NEED TO OBTAIN WRITTEN INFORMED CONSENT FOR INVASIVE NURSING PROCEDURES WITH A VIEW OF BULGARIAN LEGISLATION
}

\author{
Anna Georgieva ${ }^{1}$, Maria Valkanova ${ }^{2}$ \\ ${ }^{1}$ Department of Health Care, Faculty of Public Health, Medical University of Varna \\ ${ }^{2}$ Department of Social Medicine and Health Care Organisation, Faculty of Public Health, \\ Medical University of Varna
}

\begin{abstract}
INTRODUCTION: The study on the need to obtain written informed consent for invasive nursing procedures has important scientific and practical importance in meeting the patients' rights and achieving professional nursing security.

AIM: To examine the need to obtain written informed consent for invasive nursing manipulations with a view to the current Bulgarian legislation.

MATERIALS AND METHODS: We have conducted an analysis of the literature and used a documentary method (due diligence). The legal regulation of public relations was analyzed and was linked to the nurse's participation in the process of obtaining informed consent from the patient and in particular to the need to obtain written informed consent for invasive nursing procedures. The study is part of a complex, targeted and thorough study of the possibilities to optimize the participation of nurses in the process of obtaining informed consent from patients, conducted in the period January 2008 - September 2015.

RESULTS: As result of the legal analysis of the primary and secondary legislation of the Republic of Bulgaria on the researched problem, it was found that an essential part of the medical activities performed by the nurses belong to the so-called invasive methods. At the same time the law requires informing and obtaining consent for the aforementioned medical activities to be carried out in writing. Moreover, it is a condition regarding the reality and validity of the consent. In this case, we performed a detailed analysis on issues concerning the individual that is obliged to provide the consent when performing the invasive procedures that are written above.

CONCLUSIONS: Based on a thorough analysis of the primary and secondary legislation of the Republic of Bulgaria and also an analysis of the available scientific literature on the issue, the conclusion is that not the doctor, but the nurse is the one to inform and to obtain written consent from the patient before performing the invasive procedures for which the nurse is responsible.
\end{abstract}

Keywords: invasive procedures, nurse, patient written informed consent

\footnotetext{
Address for correspondence:

Anna Georgieva

Department of Nursing Care, Faculty of Public Health

Medical University of Varna

55 Marin Drinov St

e-mail:anngebg@gmail.com
} 
Anna Georgieva, Maria Valkanova

\section{INTRODUCTION}

The new roles and expanded competencies of the nurse determine the importance of the issue of informed consent in daily practice, especially in cases where she is the one performing interventions and manipulations with invasive nature. The study on the need to obtain written informed consent for invasive nursing procedures has the important scientific and practical importance to observe the patients rights and achieve professional nursing security.

\section{AIM}

The aim of this study is to examine the need to obtain written informed consent for invasive nursing manipulations with a view to the current Bulgarian legislation.

\section{MATERIALS AND METHODS}

We have conducted an analysis of the literature and used a documentary method (due diligence). The legal regulation of public relations was analyzed and was linked to the nurse's participation in the process of obtaining informed consent from the patient and in particular the need to obtain written informed consent for invasive nursing procedures. The study is part of a complex, targeted and thorough study of the possibilities to optimize the participation of nurses in the process of obtaining informed consent from patients, conducted in the period January 2008 - September 2015.

\section{RESULTS}

Essential in providing medical assistance to patients is the clarity and legal certainty in the work of healthcare professionals. For this task a clear and unified approach in determining the participation of nurses in the process of obtaining informed consent from patients is needed. The result from a comparative legal analysis of the legislation of the Republic of Bulgaria and the laws of Denmark, Belgium, France, Luxembourg, Quebec (Canada), Spain, Finland and Russia, is that no single approach and concept was found in the regulation of the involvement of nurses in the process of obtaining informed consent from patients in our country, unlike in the laws of other countries where it is clearly and systematically arranged (1). Foreign legal systems use different terms and systematiza- tion of the institutions, but they outline a strict legislative framework. Therefore, the attached comparative legal approach provides opportunities for raising awareness of the ways that could determine or refine considerably the institution in the Bulgarian legislation. The established legal void concerning the participation of nurses in the process of obtaining informed consent from patients necessitates further development and refinement of the existing legislation in Bulgaria, using as an example the experience of other countries (1). In this sense, it is appropriate to include obligations for all medical professionals to inform patients and to have their own consent forms, including nurses, the medical activities for which the professional is responsible, with regard to the level of competency, similar to the observed legal systems in the other countries (1).

An additional argument in support of the need for clarification and the Health Act regarding the participation of nurses in obtaining informed consent from the patient is the provision of Art. 89, para. 1 of the Health Act where "In surgery, general anesthesia, invasive and other diagnostic and therapeutic methods that lead to increased risk to life and health of the patient or to a temporary change of his mind, the information under Art. 88 states that an informed consent shall be provided in written form" (2). According to the definition of the Health Act, „invasive methods" are the diagnostic and therapeutic methods, instrumental methods that violate the integrity of the skin and mucous membranes or penetrate through natural openings into the human body (from $\$ 1$, p.2 "Additional Provisions of the Health Act) (2).

In the literature, it is assumed undoubtedly that injections belong to the invasive methods as they relate to the violation of the integrity of the skin and have a number of complications that threaten the health and lives of patients $(3,4)$.

According to the Hospital Clinical Guideline of The Royal Children's Hospital Melbourne "Putting permanent urethral catheter is an invasive procedure that should only be performed by qualified competent medical professional using aseptic technique. The catheterization of the urinary tract should only be performed when there is a specific and ade- 
quate clinical indication, as it carries a high risk of infection “(5).

The Ministry of Health and Social Development of the Russian Federation and the Russian National Research University „Pirogov“ (2011) also examined the placement of permanent urethral catheter as invasive procedure in their joint publication „Invasive Treatments - Equipment and Complications" (6).

In Mosby's Medical Dictionary (2008) the invasive procedure is defined as „A diagnostic method which penetrates a body cavity or interferes with the normal functions of the body" (7).

Under the current legislation, and in particular art. 3, para. 1, p. 5 of Ordinance No. 1 from 8 February 2011 on professional activities which the nurses, midwives, associated medical specialists and health assistants can carry out upon instruction or independent manipulations that the nurse can perform herself, the outlined activities are:

$\diamond$ injection - subcutaneously, intramuscularly, intravenously, intradermal;

$\diamond$ ensuring continuous venous access;

$\diamond$ execution of venous puncture and blood sampling;

$\diamond$ performing intravenous infusion;

$\diamond$ introduction, maintaining access and change of the urethral catheter;

$\diamond$ parenteral administration of medicinal products and infusion solutions and the like (8).

An essential part of medical activities, which the nurse provides, belong to the so-called invasive methods. In this sense, it is required, based on the Health Act, to obtain a written consent. The law requires the provision of information about these procedures to be done in a written form and it is a condition for the reality and validity of the consent in this case (2).

The question is then: Who is subject to the obligation to inform and to reach an agreement?

It would be hard to accept that for these manipulations carried out by the nurse the informed consent should be obtained by the doctor. The information for the consent along with the agreement is given by the competent medical specialist who is tasked with its implementation and who is responsible for it.
Therefore, it is more reasonable for the nurse to be the one who should inform in written form and obtain consent from the patient before performing invasive procedures such as injections, obtaining a continuous peripheral vein, venipuncture, taking venous blood, insertion of a catheter, performing enema, performing vaginal lavage and others $(3,4,5,6)$.

On one hand, the informed consent is an institute that protects the patient, ensuring the observance of the fundamental human rights, but on the other hand, it is a legal institution that transfers the risks of the respective intervention on the patient.

This once again gives rise to the need for finetuning, which leads to the obligation to make an agreement in carrying out medical activities.

\section{DISCUSSION}

The obligation to inform the patient and his/ her right to give consent to treatment are interconnected and conditioned. Typical for the general obligation of providing information, according to $M$. Valkanova is that it applies to all workers in the healthcare system, such as doctors, nurses and other staff in the health system, based on their competences (9).

According to $\mathrm{P}$. Lisaev „The principle is that the person who is responsible for carrying out the proposed medical act must provide information about it."

Undoubtedly, in most of the cases, the doctors have the obligation and the right to inform the patient. The obligations and rights of the nurses are subordinate to those of the doctors, as the need to give information occurs mostly in a hospital setting, which includes a treatment team. Even in this situation, the implementation of actions leads to the necessity of an additional special consent that the nurse should obtain. The order from the doctor to perform the procedure does not automatically mean that it is mandatory for patient to agree (10).

The need of obtaining an informed consent when performing nursing manipulations, as well as in the whole process of treatment and patient care is evidenced by data from a survey conducted by $\mathrm{S}$. Toncheva (2004). According to her, „this will create conditions for professional comfort and security in the performance of professional duties of the nurse, 
Anna Georgieva, Maria Valkanova

but also a prerequisite for a higher quality of care and trust" (11).

The results of another sociological study by $\mathrm{S}$. Tontcheva (2004) demonstrate the need to introduce a document by which the nurse will provide information to the patient about upcoming interventions and possibly obtain their consent. This document is part of the psychological preparation of patients. As stated by S. Tontcheva (2004), ,the introduction of uniform informed consent (UIC) does not replace the personal contact between the nurse and the patient, but this could save time. The proposed model of UIC will create a partnership and shared responsibility between nurses and patients regarding their health" (12).

The information above proves and substantiates the need to introduce a document to obtain informed consent from the patient for invasive nursing treatments, which guarantees the respect of the rights of the patient for invasive procedures within the professional competence of the nurse.

Implementing the method in nursing practice, on the one hand, will facilitate the legal performance of invasive procedures conducted by the nurse and on the other hand will protect her from responsibility in a risk-accompanying intervention.

According to the results of the analysis of the available literature on the problem and the laws and regulations of the Institute of Informed Consent in the context of the participation of the nurses in the procedure in the Republic of Bulgaria it is necessary de lege ferenda to further develop and refine the legislation of the Republic of Bulgaria concerning the participation of nurses in the process of obtaining informed consent from patients.

In order to guarantee the right of the patient to make a decision and protect the nurse in the performance of her professional duties in the Ordinance No. 1 from 8 February 2011 on professional activities, which the nurses, midwives, associated medical specialists and health assistants can carry out upon instruction or independently, issued by the Ministry of Health, promulgated in SG No. 15 from 18 February 2011, amended in SG No. 50 from 1 July 2011, para. 3 should be added to art. 3 containing the following: „Professional activities Art. 3, para. 1, p. 1 b. $\mathrm{d}$ that have invasive nature are carried out in accordance with Art. 89, para. 1 of the Health Act".

\section{CONCLUSION}

Based on a thorough analysis of the primary and secondary legislation of the Republic of Bulgaria and analysis of the available scientific literature on the issue we have reached to the conclusion that not the doctor, but the nurse is the one who should inform in written form and obtain consent from the patient before performing invasive treatments for which he/she is responsible. In this sense, it is necessary to further develop and refine the legislation in the Republic of Bulgaria. For this purpose, the obligation to inform and to reach an agreement is carried by every medical professional, including the nurse, for the medical activities for which she is responsible, in compliance with the level of her competences. This will increase legal certainty and clarity in the interpretation of the law. Thus, on the one hand, the responsibility will be distributed among healthcare professionals, and on the other hand - they will be better protected in carrying out medical procedures that pose a risk to the patient.

\section{REFERENCES}

1. Georgieva A, Valkanova M. Study of legal framework of involvement of nurses in the process of patient's informed consent in the Republic of Bulgaria and other countries. Scripta Scientifica Salutis Publicae. 2015; 1 (2): 47-51.

2. Health Act-SG No. 103 of 23 December 2005, last amended and supplemented SG No 1 of 3 January 2014. (in Bulgarian).

3. Jain KK. Drug Delivery Systems. Springer Science \& Business Media; 2008.

4. Kale T, Momin M. Needle free injection technology - An overvie. Innovations in pharmacy. 2014; 5 (1): Article 148. http://www.pharmacy.umn.edu/innovations/ prod / groups / cop / @ pub / @ cop / @ innov / documents / article / cop_article_473898.pdf

5. The Royal Children's Hospital Melbourne. Hospital clinical guideline. Indwelling urinary catheter - insertion and ongoing care. Australia. http:// www.rch.org. au/rchcpg/hospital_clinical_ guideline_index/Indwelling_urinary_catheter_ insertion_and_ongoing_care/.

6. Russian National Research University Pirogov. Ministry of Health and Social Development. In- 
vasive procedures - equipment and complications.

Science and Education Material. Moskva: Non-

profit organization Association of Moscow univer-

sities; 2011. (in Russian)

7. Mosby's Medical Dictionary. Invasive procedure,

$8^{\text {th }}$ edition. Elsevier; 2009. Available at: http:// med-

ical-dictionary.thefreedictionary.com/invasive

procedure.

8. Ordinance No 1 of 8 February 2011 on profession-

al activities which the nurses, midwives, associated medical specialists and health assistants can carry out upon instruction or independently, issued by the Ministry of Health, promulgated SG No 15 of 18 February 2011, amended SG No 50 of 1 July 2011. (in Bulgarian).

9. Valkanova M. Medical Law. $1^{\text {st }}$ ed. Varna: STENO; 2014. (in Bulgarian)

10. Lisaev P. Deontological Matters of Medical Practice, $I^{\text {st }}$ ed. Pleven: Photon and AYA; 2008. (in Bulgarian).

11. Toncheva S. Training Nurses to Obtain the Access to Information but Consent from the Patient. Health Economics and Management. 2004; 4 (212): 24-29. (in Bulgarian).

12. Toncheva $\mathrm{S}$, Velkova $\mathrm{R}$. The role of the nurse in receiving informed agreement from patients with large intestine operations. Military medicine. 2004; 54 (1): $32-37$. 